\title{
Nephron Prorenin Receptor Deficiency Alters Renal Medullary Endothelin-1 and Endothelin Receptor Expression
}

\author{
N. RAMKUMAR ${ }^{1}$, D. STUART ${ }^{1}$, N. ABRAHAM ${ }^{1}$, D. E. KOHAN ${ }^{1,2}$ \\ ${ }^{1}$ Division of Nephrology, University of Utah Health Sciences Center, Salt Lake City, UT, USA, \\ ${ }^{2}$ George E. Whalen Department of Veterans Affairs Medical Center, Salt Lake City, UT, USA
}

Received November 11, 2017

Accepted January 10, 2018

\begin{abstract}
Summary
The endothelin (ET) and prorenin/renin/prorenin receptor (PRR) systems have opposing physiological effects on collecting duct (CD) salt and water reabsorption. It is unknown if the CD ET and renin/PRR systems interact, hence we examined the effects of deleting $C D$ renin or nephron PRR on CD ET system components. PRR knockout (KO) mice were polyuric and had markedly increased urinary ET-1 and inner medullary CD (IMCD) ET-1 $m R N A$. PRR KO mice had greatly increased IMCD ETA receptor $m R N A$ and protein, while ETB $m R N A$ and protein were decreased. Water loaded wild-type mice with similar polyuria as PRR KO mice had modestly increased urinary ET-1 excretion and inner medullary ET-1 $m R N A$, while inner medullary ETA and ETB $m R N A$ or protein expression were unaffected. In contrast to PRR KO, CD prorenin/renin KO did not alter ET system components. Taken together, these results suggest that the nephron PRR is involved in regulating CD ET system expression, but this effect may be independent of CD-derived renin.
\end{abstract}

\section{Key words}

Endothelin • Prorenin • Collecting duct • Knockout • Receptor

\section{Corresponding author}

D. E. Kohan, Division of Nephrology, 1900 E 30 N, Salt Lake City, UT 84132. Fax: 801-581-4343. E-mail: donald.kohan@ hsc.utah.edu

\section{Introduction}

The collecting duct (CD) contains several autocrine and paracrine systems that modulate $\mathrm{Na}^{+}$transport. Many of these systems inhibit $\mathrm{CD} \mathrm{Na}{ }^{+}$and water reabsorption, amongst which the endothelin (ET) system has emerged as being of particular importance. Endothelin-1, which is produced in relatively large amounts by the $\mathrm{CD}$, acts via endothelin B (ETB) and possibly endothelin A (ETA) receptors to potently and directly inhibit epithelial $\mathrm{Na}^{+}$channel (ENaC) activity and vasopressin-stimulated water permeability (Kohan et al. 2011). In contrast, relatively few autocrine and/or paracrine systems are known to stimulate $\mathrm{CD} \mathrm{Na}{ }^{+}$and water reabsorption (Pearce et al. 2015). However, recent studies have implicated the renin/prorenin receptor (PRR) pathway as a potential enhancer of $\mathrm{CD} \mathrm{Na}{ }^{+}$and water transport (Ramkumar and Kohan 2016). This system involves prorenin, and to a lesser extent renin, binding to the PRR and exerting direct effects independent of angiotensin-II (Ang II); prorenin stimulation of the PRR directly increases $\mathrm{ENaC}$ activity and membrane aquaporin-2 expression (Ramkumar and Kohan 2016). Since, within the nephron, prorenin/renin are uniquely synthesized by the $\mathrm{CD}$, and the PRR is expressed in greatest abundance within the CD (Advani et al. 2009), the possibility exists that the CD renin/PRR system interacts with the CD ET system; such crosstalk between opposing autocrine/paracrine systems might serve to modulate one another's activity. To date, however, there is no information to our knowledge on cross-regulation between the ET and the renin/PRR systems in the CD. Studies in non-CD cells have demonstrated that ET-1 directly inhibits agonist-stimulated renin synthesis and release (juxtaglomerular apparatus cells) (Kohan et al. 2011), however there are no reports in any cell type examining renin/PRR system (independent of Ang II) regulation of the ET system. Consequently, the current study was undertaken to determine if the renin/PRR 
system is capable of modulating the ET system in the CD.

\section{Methods}

\section{Animal care}

All animal studies were conducted with the approval of the University of Utah Animal Care and Use Committees in accordance with the National Institutes of Health Guide for the Care and Use of Laboratory Animals.

\section{Generation of cell-specific KO mice}

Details about generation of nephron-specific PRR KO and CD-specific renin $\mathrm{KO}$ mice have been published (Ramkumar et al. 2015, Ramkumar et al. 2014). All mice were bred on a C57BL/6J background derived from an in-house colony. Wild-type mice were C57BL/6J with no engineered genetic modifications. Nephron-specific PRR KO mice are homozygous for loxP-flanked (floxed) exon 2 of the ATP6AP2 gene, hemizygous for the Pax8-rtTA transgene (contains the reverse tetracycline transactivator under control of the paired box gene 8 promoter) and hemizygous for the LC-1 transgene (encodes tetracycline-inducible bicistronic Cre recombinase and luciferase) (Ramkumar et al. 2015). To induce nephron-wide KO, PRR KO were given $2 \mathrm{mg} / \mathrm{ml}$ doxycycline in $2 \%$ sucrose drinking water starting at 1 month of age and continued daily for 12 days, followed by 4 weeks off doxycycline before study. Control mice were the same genotype but did not receive doxycycline. Collecting duct-specific renin $\mathrm{KO}$ mice are homozygous for floxed exon 1 of the Ren 1 gene (C57BL/6J mice do not contain the Ren2 gene) and hemizygous for Cre recombinase under the control of the aquaporin-2 (AQP2) promoter (Ramkumar et al. 2014). Controls consisted of mice homozygous for the floxed Ren1 gene but lacking the AQP2-Cre transgene. Mice from both sexes $(1: 1)$ were used for all studies. Genotyping of PRR KO, renin KO and control mice was performed as previously described (Ramkumar et al. 2015, Ramkumar et al. 2014).

\section{Metabolic cage studies}

The PRR KO, renin $\mathrm{KO}$ and control mice at 3 months of age were placed in metabolic cages for two consecutive days with free access to a gelled diet with normal sodium $(0.3 \%)$ content and drinking water. Water intake and urine volume were recorded on both days; only data from the second day was used since mice typically take a day to acclimate to the cages. Urine osmolality was measured using Osmett II (Precision System, Natick, MA, USA). Urinary ET-1 was determined by enzyme immunoassay (R\&D Systems, Minneapolis, MN, USA).

For water loading studies, wild-type mice were placed in metabolic cages for 2 days as described above, fed a normal sodium diet and drinking water, and urine collected on day 2. Mice were removed from metabolic cages and given 3 days rest. Mice were then returned to metabolic cages and started on water loading (normal sodium gelled diet plus free access to drinking water containing $5 \%$ sucrose). Mice were housed in metabolic cages on days 1 and 2, and days 6 and 7 of water loading (mice were not continuously housed in metabolic cages for all 7 days of water loading to avoid undue stress). Water intake, urine volume, urine osmolality and urine ET-1 were determined from days 2 and 7 of water loading (days 1 and 6 not recorded to allow mice a day to acclimate each time they were placed in metabolic cages).

\section{RNA analysis}

Messenger RNA levels were determined for ET-1, ETA and ETB from PRR KO and control mouse renal medulla and inner medullary $\mathrm{CD}$ (IMCD), renin $\mathrm{KO}$ and control mouse inner medulla, and wild-type mice inner medulla (all mice fed a normal sodium diet). In addition, ET-1, ETA and ETB $m R N A$ levels in inner medulla of wild-type mice on days 2 and 7 of water loading were determined. RNA was isolated using the PureLink RNA kit (Ambion, Foster City, CA, USA) and reverse transcribed using $0.5 \mu \mathrm{g}$ of total RNA with oligo(dt) and Superscript III reverse transcriptase according to the manufacturer's protocol (Invitrogen, Grand Island, NY, USA). The resulting cDNA was assayed for relative expression of ET-1, ETA, ETB and GAPDH $m R N A$ using Taqman Gene Expression Assays (ET-1 probe cat \# Mm00438656_m1, ETA probe cat\# Mm01243722_m1, ETB probe cat \# Mm00432989_m1, GAPDH probe cat \# Mm03302249_g1, Applied Biosystems, Carlsbad, CA, USA).

\section{Immunofluorescence}

Kidneys from control and PRR KO mice were fixed overnight in $10 \%$ formaldehyde, embedded in paraffin and $4 \mu \mathrm{m}$ sections obtained. Deparaffinized kidney sections were treated with $0.1 \%$ Triton for $10 \mathrm{~min}$ for antigen retrieval, blocked with Odyssey blocking 
buffer (Licor, Lincoln, NE, USA) for $1 \mathrm{~h}$ and incubated with primary antibody against ETA (1:25, Alomone, Jerusalem, Israel) and AQP2 (1:200, Santa Cruz, Dallas, TX, USA) overnight. After 3 consecutive washes of 5 min each with phosphate-buffered saline (PBS), kidney sections were incubated with secondary donkey anti- rabbit Alexa Fluor 488 (1:200) and donkey anti-goat Alexa Fluor 555 (1:400) antibodies for $60 \mathrm{~min}$. After 3 wash-rinse steps of $5 \mathrm{~min}$ each with PBS, slides were mounted in Vectashield (Vector Laboratories, Burlingame, CA, USA) and sealed with a coverslip. Tissue sections were examined and photographed with a Nikon FXA epiflourescence microscope.

\section{Western analysis}

Renal inner medullas were dissected and homogenized in ice-cold buffer $(50 \mathrm{mM}$ Tris, $50 \mathrm{mM}$ EDTA, $1 \%$ Triton, $1 \mathrm{mM}$ PMSF) and Complete Protease Inhibitors (Roche, St. Louis, MO, USA). Whole cell lysate protein content was determined using the modified Lowry assay and samples were solubilized with Laemmli loading buffer containing $0.5 \%$ lithium dodecyl sulfate. Loading control gels were initially run on $12 \%$ Bis-Tris gels, stained with Coomassie blue and random bands quantified by densitometry to assess equal loading. Equal amounts of protein (10 $\mathrm{g} / \mathrm{lane})$ were run on a denaturing NUPAGE 4-12\% Bis-Tris minigel (Invitrogen) and transferred to a polyvinylidene difluoride plus nylon membrane. Membranes were incubated with antibodies against ETA (1:100, Alomone catalog \# AER-001) or ETB (1:200, Alomone catalog \# AER-002) or mouse monoclonal $\beta$ actin (1:1000, Life Technologies, Carlsbad, CA, USA catalog \# AM4302). Secondary horseradish peroxidase-conjugated antibodies (goat anti-rabbit for ETA/B catalog \# sc-2004 and goat anti-mouse for $\beta$ actin catalog \# sc-2005, Santa Cruz, Dallas, TX, USA) were used at a dilution of 1:2000. Immunoblots were visualized with the Advance ECL system (GE Healthcare, Piscataway, NJ, USA). Densitometry was performed with a Bio-Rad gel documentation system (Hercules, CA, USA).

\section{Inner medullary collecting duct isolation}

Mouse IMCD were isolated as previously described (Strait et al. 2010). Briefly, mouse renal inner medullas were minced and incubated at $37^{\circ} \mathrm{C}$ in $0.1 \%$ collagenase (type I; Worthington, Freehold, NJ, USA) containing $0.01 \%$ DNase (type I) in Hanks' balanced salt solution (HBSS) $+15 \mathrm{mM}$ HEPES (pH 7.4). After $\sim 45 \mathrm{~min}$, the digest containing mainly single cells and tubules was filtered through a $74-\mu \mathrm{m}$ mesh, centrifuged, and suspended in $10 \%$ bovine serum albumin in HBSS, followed by two centrifuge/washes with HBSS. The final pellet containing primarily tubules was suspended in HBSS + HEPES.

\section{Statistics}

Comparisons between $\mathrm{KO}$ and their relevant control mice, as well as between water loaded and non-water loaded mice, were analyzed by the Student's t-test (unpaired, 1 tail). Data are expressed as mean \pm standard error and $\mathrm{p}<0.05$ was taken as significant.

\section{Results}

\section{PRR KO mouse studies}

A hypothesis of this study was that CD PRR modulates the CD ET system. To ideally test this in vivo, one would use CD-specific PRR targeted mice; while such mice have been developed, the deficiency of PRR during embryogenesis is cause for concern since subtle or gross developmental abnormalities can occur (Song et al. 2013). To avoid these developmental issues, mice were utilized with doxycycline-inducible PRR KO, thereby permitting gene targeting during adulthood (doxycycline started at 1 month of age in the current study). These mice have whole nephron gene targeting (Pax8 promoter drives Cre recombinase in the proximal tubule through the IMCD), hence they have PRR deleted throughout the entire nephron (no inducible CD-specific PRR targeting mice exist).

PRR KO mice have been reported to have, under physiological conditions, major alterations in water, and modest changes in sodium, metabolism (Ramkumar et al. 2015, Ramkumar et al. 2016). To confirm this, PRR KO and control mice were studied in metabolic cages; PRR KO mice had higher water intake, higher urine volume (3-4 fold), and reduced urine osmolality compared to controls (Figs 1A1-1A3) under baseline conditions (normal sodium intake and free access to drinking water). Under these same conditions, PRR KO mice had marked elevated urinary ET-1 excretion $(\sim 10$-fold vs. controls) (Fig. 2A1) and inner medullary ET-1 $m R N A$ levels (Fig. 2A2); the inner medulla was the focus of analysis since it contains predominantly CDs. PRR KO mice had a pronounced increase in inner medullary ETA $m R N A$ ( $\sim 10$-fold vs. controls) and reduced ETB $m R N A$ (0.6-fold) compared to controls (Fig. 2A2). Similar to the $m R N A$ 
levels, PRR KO mice had greatly increased inner medullary ETA protein $(\sim 20$-fold vs. controls $)$ and decreased inner medullary ETB protein compared to controls (Figs 3A1 and 3A2). To help support the notion that PRR KO modulated CD ET receptors, kidneys from PRR KO and control mice were immunostained. We were unable to obtain reliable ETB immunostaining with a variety of ETB antibodies, however ETA immunostaining was detected: there was a marked increase in CD ETA immunostaining in PRR KO mice compared to controls (sections co-labeled for aquaporin-2 to identify CDs) (Fig. 4). Note that these images show outer medulla since we were unable, for unclear reasons, to get consistent staining of inner medulla. To further confirm that IMCD was involved, IMCD were acutely isolated and ET system $m R N A$ determined (protein levels too low to use Western analysis). As shown in Figure 4, IMCD from PRR KO mice had an identical $m R N A$ pattern as seen in inner medulla - increased ET-1 and ETA $m R N A$, and reduced ETB $m R N A$, as compared to controls.

\section{Renin KO mouse studies}

Collecting duct-specific renin $\mathrm{KO}$ mice were examined in order to determine whether CD-derived renin modulates the collecting duct ET system. We have previously reported on these mice (Ramkumar et al. 2014), however to reassess urine water excretion, the major factor altered in PRR KO mice, renin $\mathrm{KO}$ mice were subjected to metabolic cage studies. No differences in water intake, urine volume or urine osmolality were observed between renin $\mathrm{KO}$ and control mice (Figs 1B1-1B3); although not reported herein, renin KO mice also do not have altered urine $\mathrm{Na}$ excretion compared to controls under physiological conditions (Ramkumar et al. 2014). Renin KO mice had no difference in urinary ET-1 excretion (Fig. 2B1) or inner medullary ET-1 $m R N A$ (Fig. 2B2) compared to controls on a normal sodium diet with free access to drinking water. Renin $\mathrm{KO}$ mice also had no alteration in ETA or ETB $m R N A$ (Fig. 2B2) or protein (Figs 3B1 and 3B2) compared to controls.
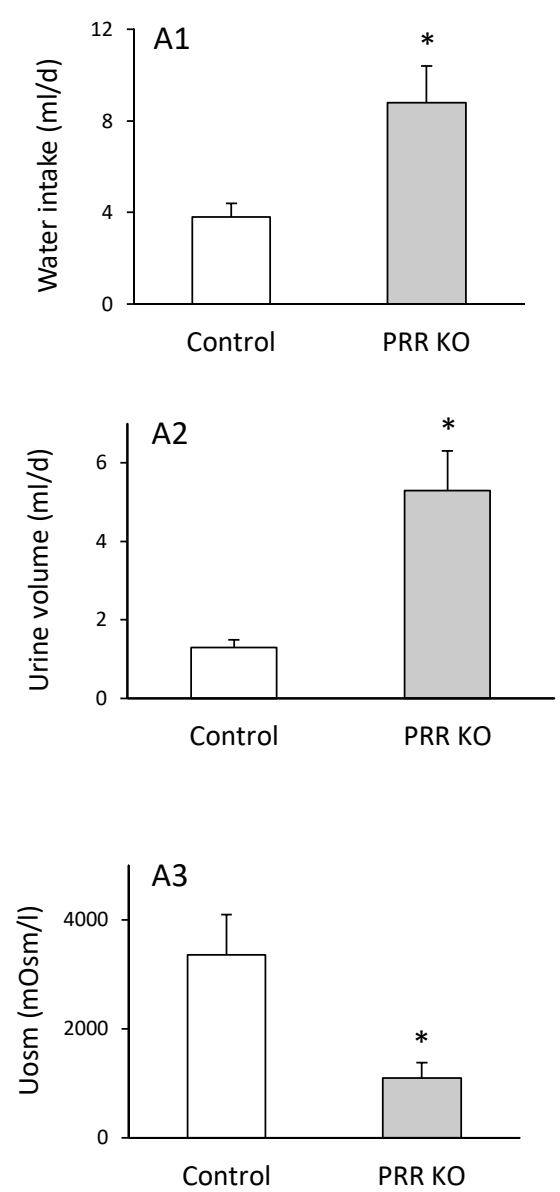
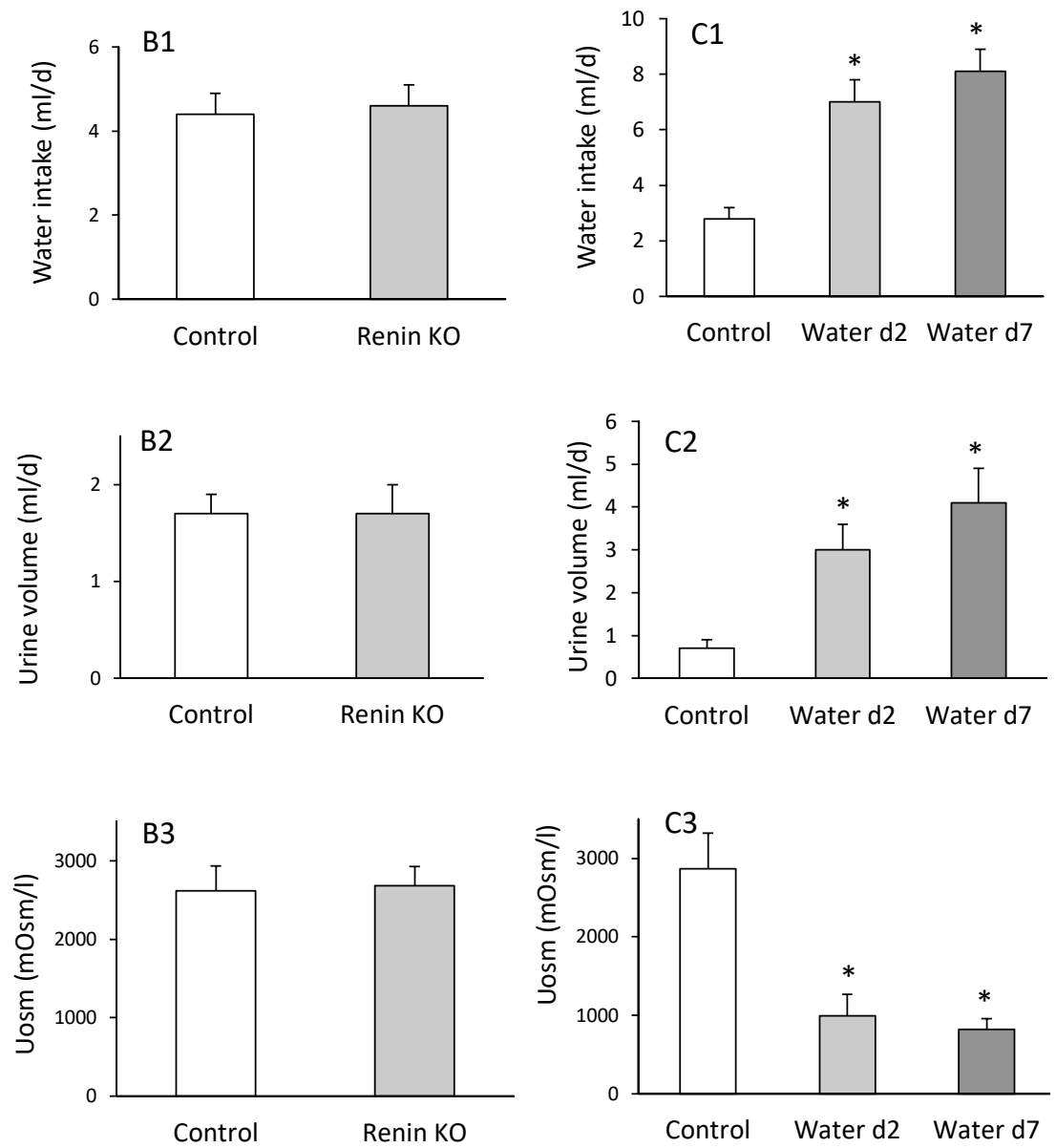

Fig. 1. Effect of nephron-specific PRR KO, collecting duct-specific renin KO and water loading in WT mice on water intake (A1-C1), urine volume (A2-C2) and urine osmolality (A3-C3). Control and PRR/renin KO mice were fed a normal sodium (0.3 \%) diet and given free access to drinking water. WT mice were fed a normal sodium ( $0.3 \%)$ diet and given free access to drinking water containing $5 \%$ sucrose for 2 or 7 days; controls were given drinking water without sucrose. $\mathrm{N}=6$ each data point. $* \mathrm{p}<0.05$ vs. control. 

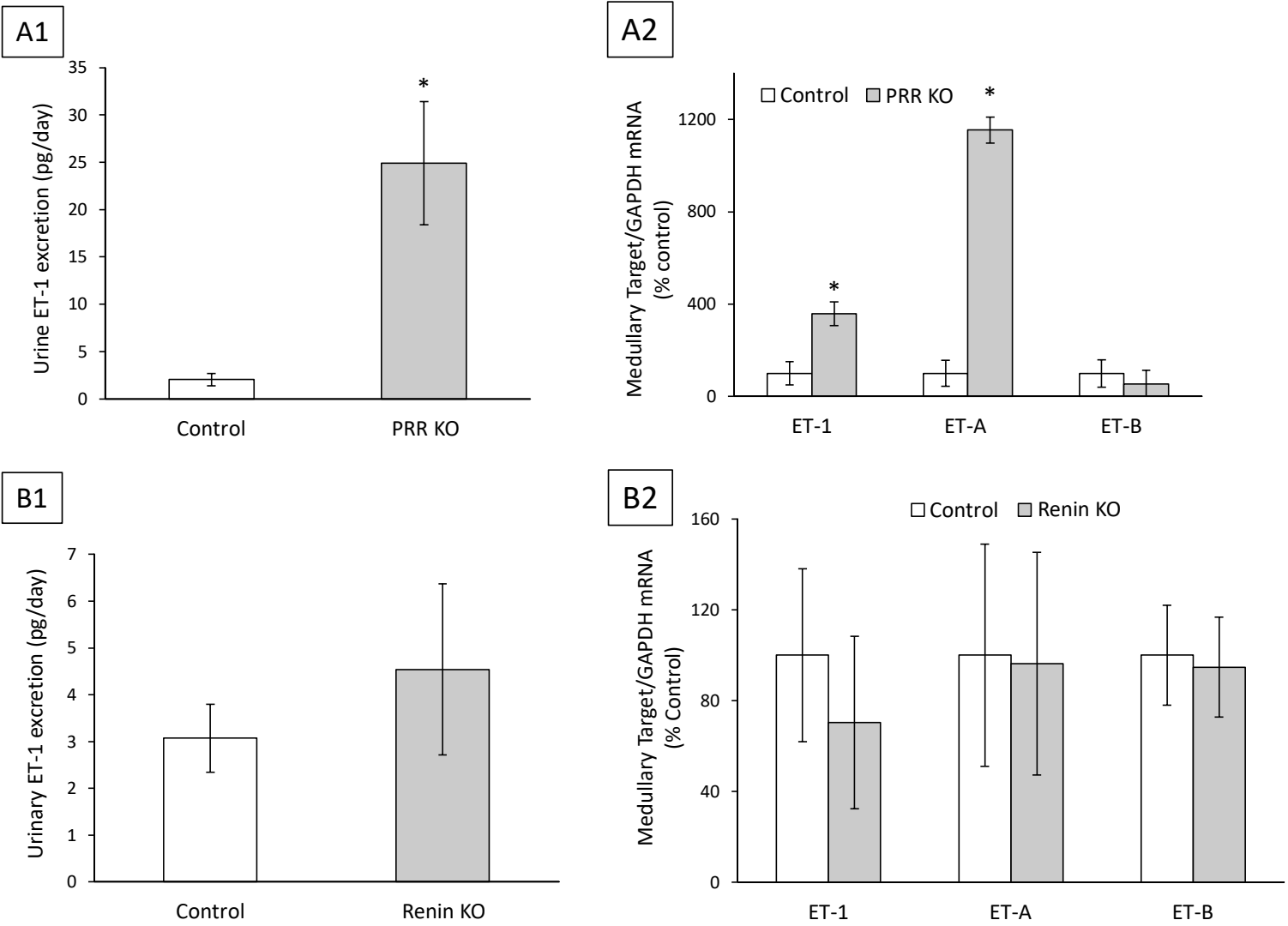

Fig. 2. Effect of nephron-specific PRR KO or collecting duct-specific renin KO on urinary ET-1 excretion (A1-B1) and inner medullary ET-1, ETA and ETB receptor $m R N A$ content (A2-B2). Control and PRR/renin KO mice were fed a normal sodium (0.3\%) diet and given free access to drinking water. $\mathrm{N}=6$ each data point. $* \mathrm{p}<0.05$ vs. control.

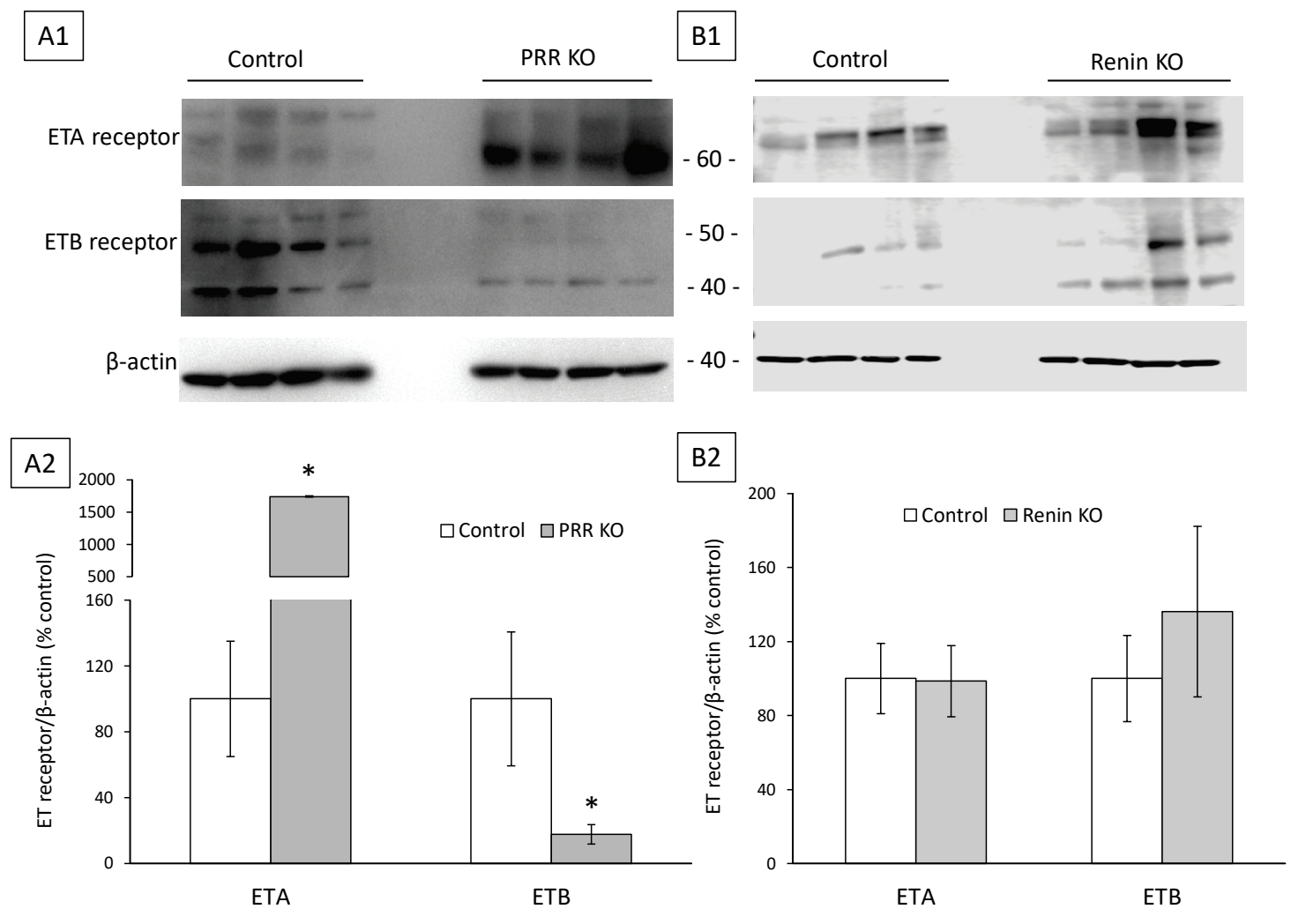

Fig. 3. Effect of nephron-specific PRR KO or collecting duct-specific renin $K O$ on inner medullary ETA and ETB receptor protein content. The Western blot is shown in Panel A1 and B1, and densitometry data in Panel A2 and B2. Control and PRR/renin KO mice were fed a normal sodium $(0.3 \%)$ diet and given free access to drinking water. $\mathrm{N}=4$ each data point. ${ }^{*} \mathrm{p}<0.05$ vs. control. 


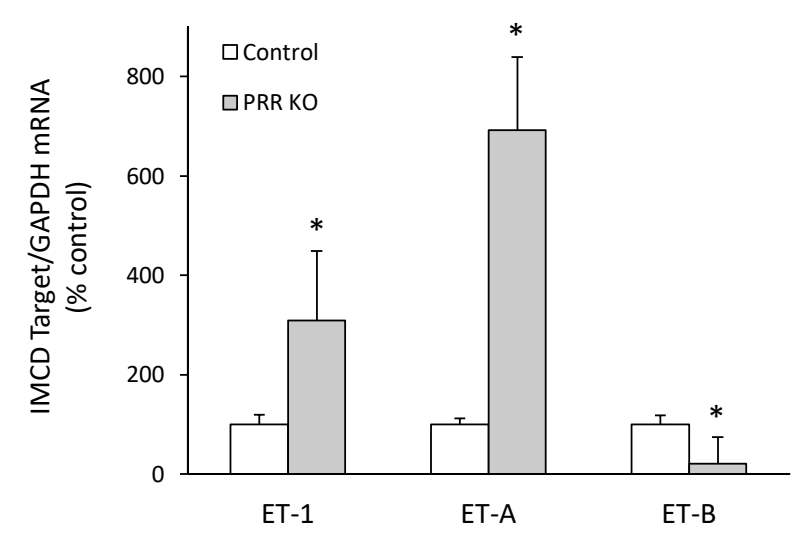

Control

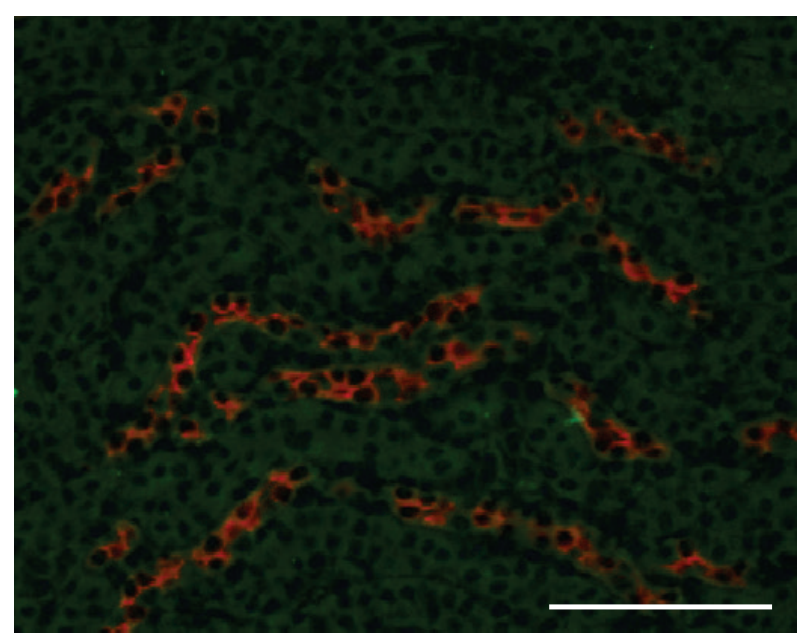

PRR KO

Fig. 4. Effect of nephron-specific PRR KO on acutely isolated mouse inner medullary collecting duct (IMCD) ET-1, ETA and ETB receptor mRNA content (upper panel) and ETA receptor immunostaining. IMCD were obtained from control and PRR KO mice fed a normal sodium $(0.3 \%)$ diet and given free access to drinking water. $\mathrm{N}=6$ each data point. $* \mathrm{p}<0.05$ vs. control. Renal medullary sections were immunostained for aquaporin-2 (red) and ETA receptor (green). Representative figures are shown from 6 separate mice with multiple sections stained in each mouse. Scale bar $=100 \mu \mathrm{m}$.

\section{Water loading studies}

The effect of water loading on renal ET system components was examined since PRR KO mice are polyuric, and diuresis has been associated with increased urinary ET-1 excretion (Lyon-Roberts et al. 2011). Administration of $5 \%$ sucrose in drinking water ad libitum resulted in water intake, urine volume and urine osmolality similar to that seen with PRR KO mice (Fig. 1C1-1C3). ET system responses were assessed on days 2 and 7 of water loading to help evaluate acute vs. chronic responses (note that it is not possible to get reliable data from day 1 of water loading since the mice need a day to adjust to the sucrose drinking water). As expected, urinary ET-1 excretion increased on both days of water loading (Fig. 5A), although to a much smaller degree than that seen with PRR KO mice (Fig. 2A1). Similarly, both days of water loading increased inner medullary ET-1 $m R N A$ (Figs 5B and 5C), although again less than that observed in PRR KO mice (Fig. 2A2). Water loading (days 2 and 7) did not alter inner medullary ETA or ETB $m R N A$ (Figs $5 \mathrm{~B}$ and $5 \mathrm{C}$ ) or protein (Figs 6A-6D).

\section{Discussion}

The current study demonstrates, for the first time, an interaction between the PRR and the CD ET systems. Mice with deletion of the nephron PRR had increased IMCD ET-1 and ETA, and decreased renal medullary ETB, expression. In contrast, $\mathrm{CD}$ renin $\mathrm{KO}$ mice had no alterations in expression of CD ET system components. Urinary ET-1 excretion was markedly enhanced in nephron PRR KO mice while it was unchanged in $\mathrm{CD}$ renin $\mathrm{KO}$ mice. Collectively, these findings suggest that the nephron PRR, but not CD-derived renin, regulates the CD ET system. 

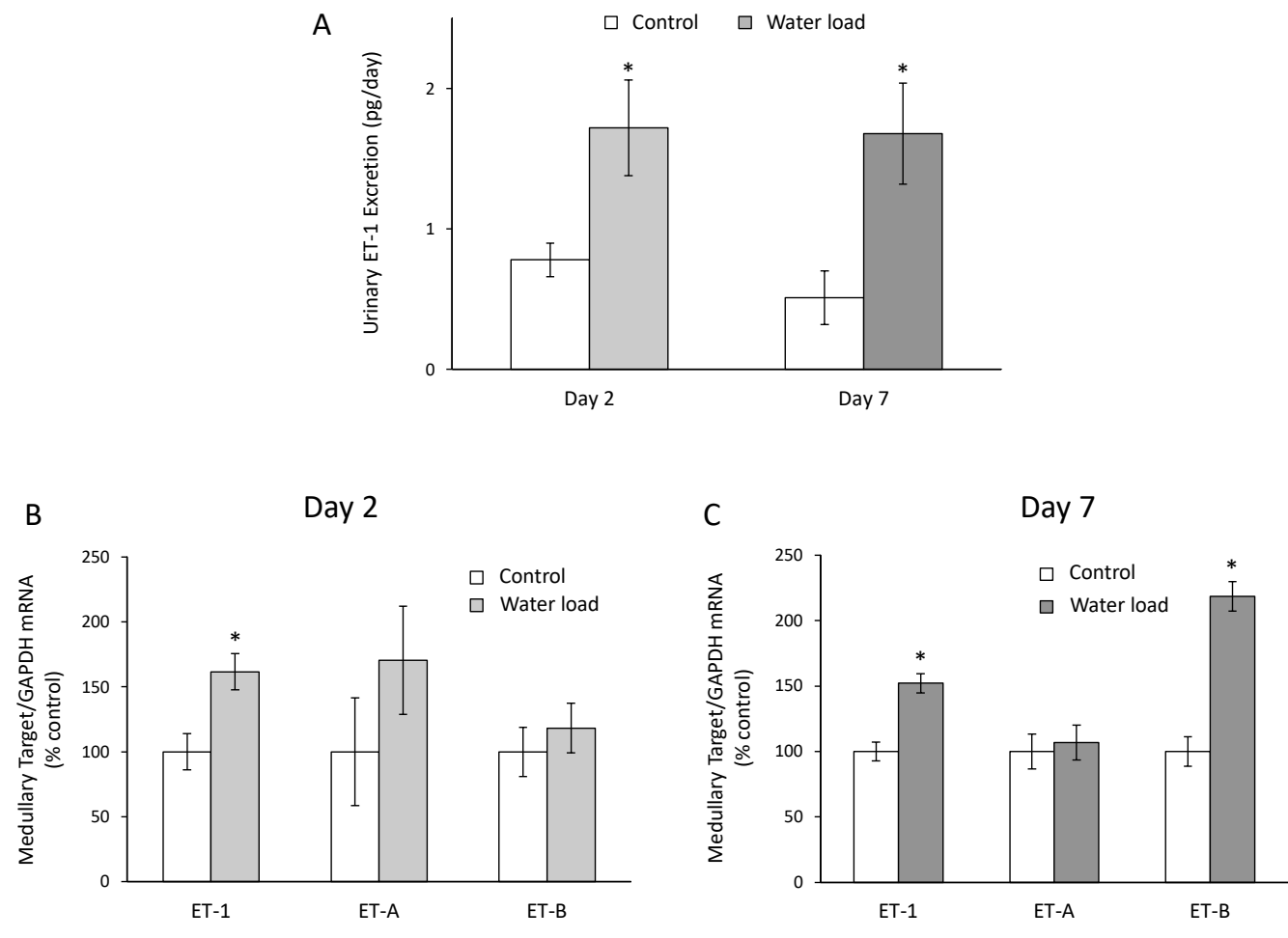

Fig. 5. Effect of water loading on urinary ET-1 excretion (A) and inner medullary ET-1, ETA and ETB receptor $m R N A$ content in wildtype mice. Mice were fed a normal sodium ( $0.3 \%$ ) diet and given free access to drinking water containing $5 \%$ sucrose for 2 days (B) or 7 days (C); controls were given drinking water without sucrose. $\mathrm{N}=6$ each data point. ${ }^{*} \mathrm{p}<0.05$ vs. control.

Day 2

A

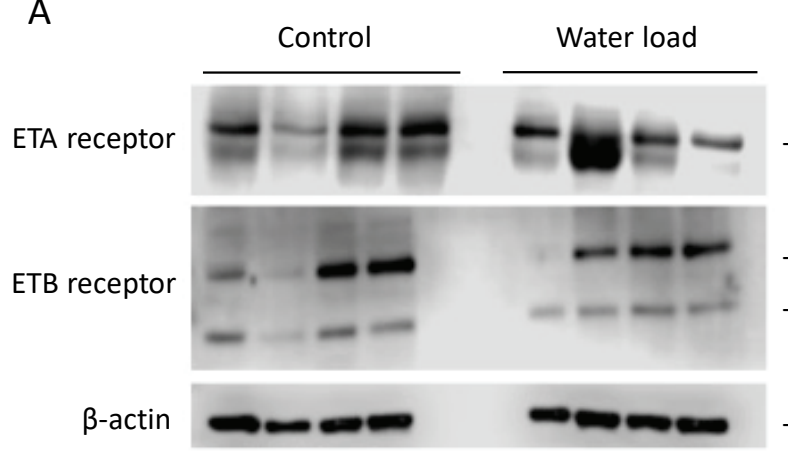

C

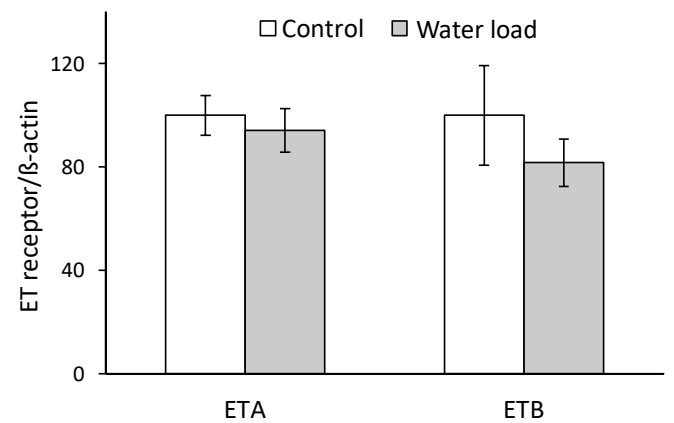

Day 7
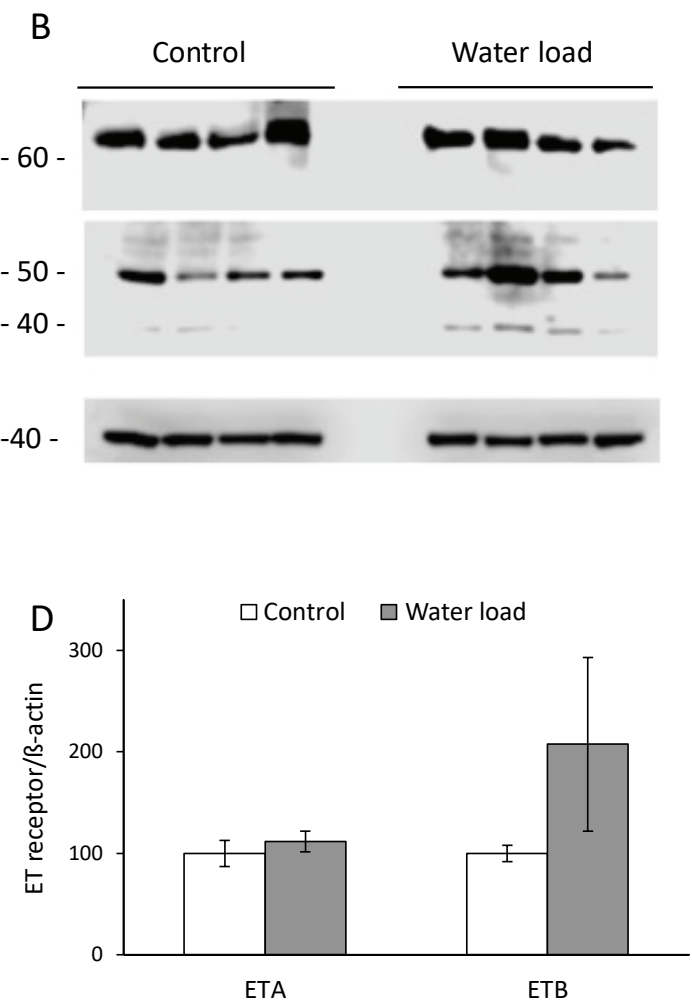

Fig. 6. Effect of water loading on inner medullary ETA and ETB receptor protein content in wild-type mice. Mice were fed a normal sodium ( $0.3 \%$ ) diet and given free access to drinking water containing $5 \%$ sucrose for 2 (A and $\mathbf{C}$ ) or 7 (B and $\mathbf{D}$ ) days; controls were given drinking water without sucrose. Western blots are shown in $\mathbf{A}$ and $\mathbf{B}$ and densitometry data for these blots shown in $\mathbf{C}$ and $\mathbf{D}$, respectively. $\mathrm{N}=4$ each data point. 
One potential explanation for ET system changes in nephron PRR KO mice relates to increased tubule and urinary flow. Previous studies have shown increased urinary ET-1 excretion following salt or water loading (Lyon-Roberts et al. 2011). This was confirmed in the present study; however the magnitude of the elevated CD and urinary ET-1 levels following water loading in wild-type mice was much less than that observed in nephron PRR KO mice. Moreover, medullary ETA and ETB expression were unaffected by water loading in wild-type mice, but were markedly altered in PRR KO mice (notably, the effect of water loading on renal medullary ET receptor expression to our knowledge has not been previously reported). Hence, it is unlikely that the diuresis in nephron PRR KO mice is directly responsible for the alterations in the CD ET system.

Another possibility is that PRR-induced signaling modulates the CD ET system. One way this could occur is through activation of PRR by renin or prorenin. We found no evidence that CD-derived prorenin or renin regulated the CD ET system; however, since filtered renin can reach the urine (Roksnoer et al. 2016) and urinary renin is still present (albeit reduced) in CD renin KO mice (Ramkumar et al. 2014), the possibility cannot be excluded that renin/prorenin binding to PRR is involved in PRR regulation of the CD ET system. Most simply, this could involve PRR activation of prorenin to promote formation of Ang II. However, although Ang II increases ET-1 production by several cell types, it was shown to either not change, or in combination with high salt intake to decrease, inner medullary ET-1 content (Sasser et al. 2002). Interestingly, Ang II increases urinary ET-1 excretion (Sasser et al. 2002). Further, Ang II decreased ETA and ETB expression in isolated IMCD (Wong and Tsui 2001). PRR signaling independent of Ang II could also potentially be involved in modulating the ET system. Prorenin activation of PRR on $\mathrm{CD}$ cells can induce prostaglandin $\mathrm{E}_{2}$, protein kinase $\mathrm{A}$, nicotinamide adenine dinucleotide phosphate oxidase 4 (NOX4), serum and glucocorticoid-regulated kinase 1 (SGK1), the Wnt/ß-catenin pathway, cyclooxygenase-2 and extracellular signal-regulated kinase 1/2 (ERK1/2) (Advani et al. 2009, Gonzalez et al. 2012, Lu et al. 2016a, Lu et al. 2016b, Wang et al. 2016). Amongst the above, CD ET-1 can be stimulated by NOX4 (Wheatley and Kohan 2017) and SGK1 (Gumz et al. 2003); however this would not explain why PRR KO increases CD ET-1. In contrast to ET-1, beyond Ang II regulation discussed above, little is known about factors controlling ET receptor expression in the CD. One possibility is that PRR deficiency in the nephron PRR KO mice reduces autophagosomal function (Trepiccione et al. 2016) leading to increased accumulation of at least ETA (would not explain the decrease in ETB). However, ETA $m R N A$ is increased in nephron PRR KO mice, so at least a transcriptional and/or translational effect is involved.

The physiological significance of PRR differential regulation of CD ETA and ETB is unknown. As discussed earlier, one might speculate that the PRR and ET systems interact to regulate renal salt and/or water excretion. In general, under physiological conditions, the natriuretic and diuretic effects of ET-1 on the CD are thought to be primarily due to ETB receptor activation, albeit ETA receptors have also been implicated (reviewed in Kohan et al. 2011, Lynch et al. 2013, Stuart et al. 2013); it is unclear what the net effect of PRR would be on ET system activation with respect to salt and water excretion. Further, it is unclear if the effects of PRR KO on ET receptors are separately mediated or if primary modulation of one receptor might induce compensatory changes in the other (e.g. PRR signaling may directly affect ET-1 and ETA with secondary compensatory changes in ETB). Another possibility is that PRR regulates the CD ET system for purposes independent of renal salt and/or water excretion. Both PRR (Li et al. 2017) and ET-1 (via ETA) (Culshaw et al. 2015) have been shown to promote renal pro-fibrotic pathways, while renal ETB may exert anti-fibrotic effects (Forbes et al. 2001). Hence, it may be that PRR activation that favors fibrosis may lead to downregulation of CD ET-1/ETA and upregulation of CD ETB as compensatory antifibrotic responses. Clearly, further investigation of these possibilities is needed, albeit beyond the scope of the current study.

\section{Conflict of Interest}

There is no conflict of interest.

\section{Acknowledgements}

These studies were supported by funding from the American Society of Nephrology (N.R.), a VA Merit Review (D.E.K.) and National Institutes of Health P01 HL136267 (D.E.K.). 


\section{References}

ADVANI A, KELLY DJ, COX AJ, WHITE KE, ADVANI SL, THAI K, CONNELLY KA, YUEN D, TROGADIS J, HERZENBERG AM, KULISZEWSKI MA, LEONG-POI H, GILBERT RE: The (pro)renin receptor: site-specific and functional linkage to the vacuolar $\mathrm{H}^{+}$-ATPase in the kidney. Hypertension 54: 261-269, 2009.

CULSHAW GJ, MACINTYRE IM, DHAUN N, WEBB DJ: Endothelin in nondiabetic chronic kidney disease: preclinical and clinical studies. Semin Nephrol 35: 176-187, 2015.

FORBES J, HEWITSON T, BECKER G, JONES C: Simultaneous blockade of endothelin A and B receptors in ischemic acute renal failure is detrimental to long-term kidney function. Kidney Int 59: 1333-1341, 2001.

GONZALEZ AA, LUFFMAN C, BOURGEOIS CR, VIO CP, PRIETO MC: Angiotensin II-independent upregulation of cyclooxygenase-2 by activation of the (pro)renin receptor in rat renal inner medullary cells. Hypertension 61: 443-449, 2013.

GUMZ ML, POPP MP, WINGO CS, CAIN BD: Early transcriptional effects of aldosterone in a mouse inner medullary collecting duct cell line. Am J Physiol Renal Physiol 285: F664-F673, 2003.

KOHAN DE, ROSSI NF, INSCHO EW, POLLOCK DM: Regulation of blood pressure and salt homeostasis by endothelin. Physiol Rev 91: 1-77, 2011.

LI Z, ZHOU L, WANG Y, MIAO J, HONG X, HOU FF, LIU Y: (Pro)renin receptor is an amplifier of Wnt/betacatenin signaling in kidney injury and fibrosis. J Am Soc Nephrol 28: 2393-2408, 2017.

LU X, WANG F, LIU M, YANG KT, NAU A, KOHAN DE, REESE V, RICHARDSON RS, YANG T: Activation of $\mathrm{ENaC}$ in collecting duct cells by prorenin and its receptor PRR: involvement of Nox4-derived hydrogen peroxide. Am J Physiol Renal Physiol 310: F1243-F1250, 2016a.

LU X, WANG F, XU C, SOODVILAI S, PENG K, SU J, ZHAO L, YANG KT, FENG Y, ZHOU SF, GUSTAFSSON JA, YANG T: Soluble (pro)renin receptor via beta-catenin enhances urine concentration capability as a target of liver X receptor. Proc Natl Acad Sci U S A 113: E1898-E1906, 2016b.

LYNCH IJ, WELCH AK, KOHAN DE, CAIN BD, WINGO CS: Endothelin-1 inhibits sodium reabsorption by ETA and ETB receptors in the mouse cortical collecting duct. Am J Physiol Renal Physiol 15: F568-F573, 2013.

LYON-ROBERTS B, STRAIT KA, VAN PEURSEM E, KITTIKULSUTH W, POLLOCK JS, POLLOCK DM, KOHAN DE: Flow regulation of collecting duct endothelin-1 production. Am J Physiol Renal Physiol 300: F650-F656, 2011.

PEARCE D, SOUNDARARAJAN R, TRIMPERT C, KASHLAN OB, DEEN PM, KOHAN DE: Collecting duct principal cell transport processes and their regulation. Clin J Am Soc Nephrol 10: 135-146, 2015.

RAMKUMAR N, KOHAN DE: The nephron (pro)renin receptor: function and significance. Am J Physiol Renal Physiol 311: F1145-F1148, 2016.

RAMKUMAR N, STUART D, REES S, HOEK AV, SIGMUND CD, KOHAN DE: Collecting duct-specific knockout of renin attenuates angiotensin II-induced hypertension. Am J Physiol Renal Physiol 307: F931-F938, 2014.

RAMKUMAR N, STUART D, CALQUIN M, QUADRI S, WANG S, VAN HOEK AN, SIRAGY HM, ICHIHARA A, KOHAN DE: Nephron-specific deletion of the prorenin receptor causes a urine concentration defect. $A m J$ Physiol Renal Physiol 309: F48-F56, 2015.

RAMKUMAR N, STUART D, MIRONOVA E, BUGAY V, WANG S, ABRAHAM N, ICHIHARA A, STOCKAND JD, KOHAN DE: Renal tubular epithelial cell prorenin receptor regulates blood pressure and sodium transport. Am J Physiol Renal Physiol 311: F186-F194, 2016.

ROKSNOER LC, HEIJNEN BF, NAKANO D, PETI-PETERDI J, WALSH SB, GARRELDS IM, VAN GOOL JM, ZIETSE R, STRUIJKER-BOUDIER HA, HOORN EJ, DANSER AH: On the origin of urinary renin: a translational approach. Hypertension 67: 927-933, 2016.

SASSER J, POLLOCK J, POLLOCK D: Renal endothelin in chronic angiotensin II hypertension. Am J Physiol 283: R243-R248, 2002.

SONG R, PRESTON G, ICHIHARA A, YOSYPIV IV: Deletion of the prorenin receptor from the ureteric bud causes renal hypodysplasia. PLoS One 8: e63835, 2013.

STRAIT KA, STRICKLETT PK, CHAPMAN M, KOHAN DE: Characterization of vasopressin-responsive collecting duct adenylyl cyclases in the mouse. Am J Physiol Renal Physiol 298: F859-F867, 2010. 
STUART D, CHAPMAN M, REES S, WOODWARD SK, KOHAN DE: Myocardial, smooth muscle, nephron and collecting duct gene targeting reveals the organ sites of endothelin A receptor antagonist fluid retention. J Pharmacol Exp Ther 346: 182-189, 2013.

TREPICCIONE F, GERBER SD, GRAHAMMER F, LOPEZ-CAYUQUEO KI, BAUDRIE V, PAUNESCU TG, CAPEN DE, PICARD N, ALEXANDER RT, HUBER TB, CHAMBREY R, BROWN D, HOUILLIER P, ELADARI D, SIMONS M: Renal Atp6ap2/(pro)renin receptor is required for normal vacuolar $\mathrm{H}^{+}$-ATPase function but not for the renin-angiotensin system. J Am Soc Nephrol 27: 3320-3330, 2016.

WANG F, LU X, PENG K, FANG H, ZHOU L, SU J, NAU A, YANG KT, ICHIHARA A, LU A, ZHOU SF, YANG $\mathrm{T}$ : Antidiuretic action of collecting duct (pro)renin receptor downstream of vasopressin and $\mathrm{PGE}_{2}$ receptor $\mathrm{EP}_{4}$. J Am Soc Nephrol 27: 3022-3034, 2016.

WHEATLEY W, KOHAN DE: Role for reactive oxygen species in flow-stimulated inner medullary collecting duct endothelin-1 production. Am J Physiol Renal Physiol 313: F514-F521, 2017.

WONG NL, TSUI JK: Angiotensin regulates endothelin-B receptor in rat inner medullary collecting duct. Metabolism 50: 661-666, 2001. 